\title{
Consumers' anger and coping strategies following appraisals of appliance failure
}

Suné Donoghue and Helena M de Klerk

Department of Consumer Science, University of Pretoria, 0002, South Africa

\section{Correspondence}

Suné Donoghue

Department of Consumer Science

Old Agricultural Building, Room 3-14

University of Pretoria

0002

South Africa

E-mail: sune.donoghue@up.ac.za

Tel: $\quad+27124202488$

Fax: $\quad+27124202853$

\begin{abstract}
With the disconfirmation paradigm, Day and Landon's (1977) taxonomy of complaint behaviour and the cognitive appraisal theory developed by Lazarus and colleagues as theoretical approach, this study explored and described consumers' anger and coping strategies following appraisals of appliance failure. In addition, consumers' reasons for engaging in particular complaint behavioural responses were investigated in terms of the cognitive and emotional types of reasoning underlying the different coping behaviours. A cross-sectional survey was conducted amongst consumers who were dissatisfied with the performance of a major household appliance item and who resided in a major metropolitan area in South Africa. A self-administered questionnaire was distributed by means of convenience sampling, which generated 216 usable responses. The results emphasise the importance of understanding consumers' reasoning behind their choice of a specific coping strategy. Respondents who took formal complaint action engaged in problem-focused coping and those who took private
\end{abstract}


action engaged in emotion-focused coping and avoidance coping. Those who took no action experienced lower levels of anger.

Keywords: cognitive appraisal theory, appliance failure, appraisals, anger, coping strategies, complaint behaviour

\section{$1 \quad$ Introduction}

Considering letters of complaint in the consumer columns of major South African newspapers as well as online letters to consumer complaint websites and consumer bodies, it is clear that South African consumers experience a considerable number of problems with the performance of major household appliances (i.e. kitchen and laundry appliances). These problems are likely to multiply as the demand for appliances is escalating due to the availability of credit to the expanding middle class and the new socio-political dispensation's continuous large-scale electrification efforts since 2002 (Nieftagodien and Van der Berg, 2007).

The new South African Consumer Protection Act came into effect in April 2011; South African consumers can now claim to be among the best protected consumers in the world. It is, however, an undeniable fact that consumers are often still unaware of their rights, while very little is known about the dissatisfied consumer's cognitions, emotions and coping strategies in the form of complaint actions following dissatisfaction with the performance of complicated and expensive products.

The expectancy disconfirmation paradigm and Day and Landon's (1977) taxonomy of consumer complaint behaviour have been widely employed in marketing and consumer complaint research to explain how consumers reach dissatisfaction decisions and decide on the complaint path to respond to their dissatisfaction (Laufer, 2002). Another important theory to explain consumers' postconsumption reactions, is appraisal theory (Bagozzi, Gopinath and Nyer, 1999). Cognitive appraisal theory, popularised by Lazarus and colleagues, has been applied in various disciplines to understand people's emotions and behaviour when they are confronted with a stressful situation (Watson and Spence, 2007). In terms of the cognitive appraisal theory, emotions arise in response to appraisals one 
makes for something of relevance to one's well-being (Bagozzi, Gürhan-Canli and Priester, 2002), and once elicited, emotions prepare one to cope in an adaptive manner (Soscia, 2007). In a consumer complaint behaviour context, a dissatisfying consumption experience serves as the potentially stressful event that will be evaluated via the cognitive appraisal process, and complaining behaviour represents the coping mechanisms consumers use to deal with unfavourable consumption situations and the accompanying emotions (Stephens and Gwinner, 1998). Researchers propose that the cognitive appraisal approach is "an especially relevant approach for understanding the emotional responses of consumers in the marketplace" (Johnson and Stewart, 2005, p. 3) and "offers a more complete explanation of consumers' behavioural responses to emotions than other approaches used to study emotions" (Watson and Spence, 2007, p. 488).

The purpose of this research was therefore to explore and describe consumers' anger and coping strategies following appraisal of appliance failure. In addition, consumers' reasons for engaging in particular complaint behavioural responses were investigated in terms of the cognitive and emotional types of reasoning underlying the different coping behaviours. The disconfirmation paradigm, Day and Landon's (1977) taxonomy of complaint behaviour and the cognitive appraisal theory developed by Lazarus and colleagues (Folkman, Lazarus, Dunkel-Schetter, Delongis \& Gruen, 1986; Lazarus \& Lazarus, 1994) served as theoretical background for this research.

\section{LITERATURE BACKGROUND}

\subsection{The expectancy disconfirmation paradigm}

According to the expectancy disconfirmation paradigm, consumers enter into a consumption experience with predetermined cognitive expectations of a product's performance that are compared with the perceived product performance (Laufer, 2002). When performance perceptions do not meet expectations, negative disconfirmation occurs, leading to feelings of dissatisfaction (Laufer, 2002). Although dissatisfaction would appear to be an important variable in linking product selection with negative outcomes such as negative word of mouth and complaining, specific emotions such as anger and disgust are often much more strongly linked to behaviour (Bagozzi et al., 1999). 


\subsection{Consumer complaint behaviour (CCB)}

Once dissatisfaction occurs, consumers may engage in behavioural and non-behavioural responses to resolve it (Broadbridge and Marshall, 1995). Under Day and Landon's (1977) taxonomy of consumer complaint behaviour, consumers may engage in private actions and/or engage in public action such as seeking redress directly from the retailer or manufacturer, or contacting a third party. Alternatively, consumers may refrain from taking action by rationalising and forgetting about the product failure.

Many factors, such as product-specific variables, redress environment variables, and consumer-related variables, influence dissatisfied consumers' decisions about engaging in specific complaint action (Donoghue and De Klerk, 2009). Broadbridge and Marshall's (1995) study illustrated that the product-specific factors of appliances had a major influence on whether dissatisfied consumers sought redress, complained publicly and/or privately, or did nothing. With regard to the redress environment, consumers' evaluation of retailers' responsiveness to their complaint in terms of the fairness of the redress offered and the fairness of the procedures used in settling complaints, will largely determine whether that consumer will engage in consumer complaint behaviour (Kim, Wang and Mattila; 2010). If the complaint handling mechanism for the unsatisfactory product does not cause the consumer to go through a great deal of inconvenience, the likelihood of formal complaining may be increased (Huppertz, 2003). On a personal level, studies show that consumers will typically tell their story to other people to obtain emotional support (Donoghue, 2008; p. 175). Reasons why dissatisfied consumers do not complain include consumers' perceptions that complaining would not be worth their time and effort (Kim, Kim, Im and Shin, 2003). Other possible explanations include the emotional difficulties that individuals encounter when complaining and a cultural viewpoint of inappropriateness in doing so (Kim et al., 2003).

\subsection{Cognitive appraisal theory}

Cognitive appraisal is seen as "a process through which the person evaluates whether a particular encounter with the environment is relevant to his/her well-being, and if so, in what ways" (Folkman et al., 1986, p. 992). An encounter with the environment that exceeds or taxes an 
individual's resources and endangers his/her well-being may result in psychological stress. Cognitive appraisal consists of a two-part process. During primary appraisal the person determines whether the encounter is primarily harmful or threatening. The emotional consequences of primary appraisal are relatively primitive, being simple reactions to potential harm or benefit. Secondary appraisal is a complex evaluative process that takes into account the available coping options, the likelihood that a given coping mechanism will accomplish what it is supposed to, and the likelihood that one can apply a particular strategy or a set of strategies effectively. Primary and secondary appraisals converge to determine whether the person-environment transaction is stressful (Lazarus and Lazarus, 1994, pp. 143-145).

Coping is the process through which the individual manages the specific external and/or internal demands of the person-environment relationship that are appraised as stressful, and the emotion these demands generate (Stephens and Gwinner, 1998). Coping strategies are the cognitive and emotional attempts undertaken by the individual to manage the demands of the stressful situation (Mathur et al., 1999). Lazarus and Folkman (1984) identified two types of coping strategies, namely problem-focused coping (directed at managing or altering the problem causing the stress) and emotion-focused coping (directed at regulating the emotional response to the problem). Whereas researchers such as Lazarus and Folkman (1984) considered avoidance a type of emotional coping, others have argued that avoidance coping should be considered a separate coping strategy (Mathur et al., 1999). Avoidance coping implies that the person simply leaves the situation (Bagozzi et al., 2002, pp. 41-42). However, to engage in coping strategies, the individual needs to know who is to blame for the specific stressful event (Watson and Spence, 2007).

Stephens and Gwinner (1998) propose that a dissatisfying marketplace experience serves as the potentially stressful event that will be evaluated via the cognitive appraisal process. The term dissatisfying marketplace experience refers to those consumption events in which consumers' perceptions of performance compare negatively to some standard and performance is therefore evaluated as dissatisfying (Stephens and Gwinner, 1998). In a consumer behaviour context, specifically with regard to product performance failure, the specific emotions that result from cognitive appraisal vary according to the attribution of responsibility/accountability for the stressful situation. For example, it is proposed that anger results from a negative outcome (in this case product 
failure) that is perceived as controllable by others, whereas guilt and shame results from a negative outcome attributed to internal and controllable factors (Folkes, 1984; Nyer, 1997). In addition, when consumers know who is to be blamed for the product failure, they will have a target for their coping action (Forrester and Maute, 2001). Different emotions tend to be associated with different patterns of behaviour, implying that different emotions call for very different coping strategies (Bagozzi et al., 2002, p. 39).

In the context of the cognitive appraisal theory, consumers' complaint behaviour is considered to be coping behaviours. With regard to product performance failure, specific coping behaviours associated with each of the three general coping strategies (problem-focused, emotion-focused and avoidance) have been identified (Stephens and Gwinner, 1998; Kim et al., 2010). Empirical findings related to coping styles suggest that consumers may rely on more than one form of coping when managing stressful encounters. For example, consumers employ the problem-focused coping strategy when they deal squarely with the problem by taking direct action or by making plans to take action. The focus of such a coping strategy is external, aimed at the other party. Direct action consists of voicing displeasure to the offending party in the form of face-to-face, phone or mail-based complaint contact(s) to obtain redress (Stephens and Gwinner, 1998). Additionally, when consumers contact the retailer/manufacturer to complain for reasons other than seeking redress, or contact a third party to exert their rights as consumers and to object after efforts to obtain redress/compensation for the product had failed, they engage in problem-focused coping (Donoghue, 2008, p. 182).

In contrast to problem-focused coping, the emotion-focused coping strategy is directed inward. In this strategy, individuals attempt to regulate their mental response to the problem to feel better. Instead of doing something about the problem, they keep "quiet" and engage in any one of several self-deceptions such as denial or self-blame (Lazarus and Folkman, 1984:150-152). If emotion-focused coping is successful, the unhappy situation still exists, but the way the individual thinks about it has changed. People generally seek social support about a dissatisfactory product experience from their friends, family and/or acquaintances "to feel less disappointed about the self or the situation" and "to get rid of anger/frustration" (Donoghue, 2008, p. 175).

Consumers typically do not take any complaint action concerning product failures when product guarantees had expired, and when they believe that complaining is not worth their time and 
effort and that they would not achieve any resolution (Stephens and Gwinner, 1998;). Consumers might switch between brands or stop supporting retailers when they perceive that the brand name concerned is unreliable or the retailers are not trustworthy, respectively. The reasons for these particular complaint actions are associated with the avoidance coping strategy, since these people do not deceive themselves by repositioning the event in a positive light or telling themselves that they are to blame; instead, they simply avoid or walk away from the situation (Forrester and Maute, 2001).

\section{$3 \quad$ Methodology}

As very little is known about how consumers react to appliances' failures, the researchers decided on a descriptive study that could shed light on dissatisfied consumers' cognitions, the anger they experience and their coping strategies. A cross-sectional survey was therefore done to explore and describe consumers' blame attributions, anger and coping strategies following their dissatisfaction with the performance of a major electrical household appliance item during a four-year recall period. Only the emotion of anger was of interest. Future research could include other negative consumption emotions, such as frustration, disgust, surprise, shame and sadness. This methodology is regularly used in CCB studies to capture "real life" reactions compared to the artificial emotions and behaviours that are generated via experimental procedures (Del Río-Lanza, Vázquez-Casielles and Díaz-Martín, 2009).

Respondents had to be older than 25 years and had to reside in middle- to upper-income suburbs across Tshwane, a major metropolitan area in South Africa. Another condition for inclusion of respondents was that they had to have experienced dissatisfaction with the performance of a major household appliance item within a four-year recall period. This time dimension was deemed appropriate since consumers' assessment of their dissatisfaction with the actual performance of household appliances is an evolving process and problems may not appear until the product has been used for a period of time (Broadbridge and Marshall, 1995). Even though memory decay may be a potential source of bias in respondents' responses, retrospective measurements are regularly employed in CCB studies, as opposed to simulation or role-playing methodologies and experimental manipulation, because they appear relevant to those who take part in them and reflect "real life" 
reactions (in this case: actual product performance appraisals, emotions and behaviours) (Weiner, 2000, p. 387).

Given that a random sample of the general population would be unlikely to result in a significant number of respondents with dissatisfactory experiences (Del Río-Lanza et al., 2009), convenience sampling was employed, posing a limitation in terms of the generalisability of the data. The questionnaire was pre-tested to reduce error through possible misinterpretation of constructs. Fieldworkers delivered questionnaires by hand after pre-screening respondents to ensure that only dissatisfied respondents were included. Fieldworkers collected 216 useful questionnaires between February and April 2006.

The demographic characteristics indicated that the respondents were a diverse group of people. The sample consisted of $70 \%$ females and $30 \%$ males. The age of the participants ranged between 25 and 83 years, with a heavy concentration (72\%) between 25 and 45 . Respondents fell into various education groups, with $21 \%$ having as highest level of education a secondary school certificate up to Grade 12, 36\% having Grade 12 plus an additional certificate(s)/diploma(s), and $43 \%$ having either a Bachelors degree or a post-graduate qualification. A total of $53 \%$ of the respondents fell in the monthly household income category of R 2 000-R 10000 (240-1250 USD) and 47\% in the category of R 10001 or more. A total of $69 \%$ of the respondents were Caucasian, while $31 \%$ were African. The relationships between these demographic characteristics and blame attributions, level of anger and choice of coping strategies, were not part of this paper, but will be explored in a future paper.

The questionnaire was compiled after an in-depth review of the literature concerning the disconfirmation paradigm, Day and Landon's (1977) taxonomy of complaint behaviour, the cognitive appraisal theory developed by Lazarus and colleagues (Folkman et al., 1986; Lazarus and Lazarus, 1994), and CCB theory in general to determine why consumers engage in particular complaint actions. The questionnaire measured respondents' blame attributions, anger experienced and coping strategies employed following appraisals of appliance performance failures. In addition, reasons for engaging in particular complaint action were determined.

To determine respondents' blame attributions for appliance failures, they were asked to recall an appliance performance failure and to indicate the party who they believed was responsible for the 
appliance's performance failure, from a list provided. The options included the manufacturer, the purchaser, other people, the appliance item itself or other parties.

Anger experienced due to the appliance's poor/faulty performance was measured on a 4-point unipolar scale (i.e. $1=$ not angry at all; $4=$ extremely angry).

Specific coping behaviours associated with each of the three general coping strategies have been identified in a complaint behaviour context. Behaviours associated with problem-focused coping included: contacting the retailer/manufacturer to obtain redress, contacting the retailer/manufacturer for reasons other than seeking redress, contacting a repair service other than that supplied by the retailer/manufacturer, contacting a consumer protection department, writing a letter to the media or a consumer complaint website, and contacting a legal representative. Behaviours associated with emotion-focused coping included telling friends, family and/or acquaintances about the stressful experience. Behaviours associated with avoidance coping included: taking no action, switching to a different brand name and not patronising the retailer where the product was purchased anymore (Stephens and Gwinner, 1998). To determine the specific coping strategies that respondents engaged in, their behavioural and non-behavioural complaint actions taken in response to their dissatisfaction were determined first and then categorised in terms of the different types of coping strategies. Respondents' complaint behaviour was measured by using Day and Landon's (1977) taxonomy of consumer complaint behaviour: respondents had to consider a list of actual actions taken in response to their dissatisfaction, and indicate what actions, if any, were taken (multiple response questions). A nominal (yes/no) scale was used to classify the answer to each type of action taken. The response option for no action vs. action included: "Did you take any action?". The response options for private action included: "Did you tell your friends, family and/or acquaintances about the bad experience?", "Did you decide to use another brand name?", "Did you stop supporting the retailer where the appliance was purchased?". The response options for public action included: "Did you contact the retailer/manufacturer to obtain redress (repairs/replacement/refund)?", "Did you contact the retailer/manufacturer to complain for reasons other than seeking redress?", "Did you contact a repair service other than that supplied by the retailer or manufacturer?", "Did you contact a consumer protection organisation/department?", "Did you write a letter to the press (newspaper, magazine etc.) or to a consumer complaint website?" and “Did you contact a legal representative?". 
Respondents who did not take any action and those who engaged in private or public action were asked to select the reason(s) for the particular complaint action(s) taken, again from a list provided by the researcher. An open-ended response option was also included for each type of action taken, to ensure that all possible reasons were included. The reasons for engaging in a particular complaint action were categorised in terms of cognitive (rational) reasoning and emotional reasoning and relevant coping strategies. Reasoning (ways of thinking) in this sense refers to mental processes.

Descriptive statistics and Chi-square tests for equal proportions were performed to analyse and interpret the data ( $\mathrm{p}$-value significant at 5\%).

\section{$4 \quad$ Findings}

The majority of the respondents $(62.8 \%)$ blamed the manufacturers for the appliance performance failures, compared to human error (13.0\%), the appliance's (21.9\%) faulty performance, and other reasons $(2.3 \%)$. With regard to the appraisal theory; when consumers know or have decided who is to blame for the product failure they will have a target for their coping action and will therefore know what type of complaint action to take to deal with the stressful situation (Forrester and Maute, 2001). As most of the respondents $(84.7 \%)$ felt that either the manufacturer or the product itself was to be blamed for the problem, one would expect them to inform the retailer or manufacturer of the problem. Against Day and Landon's (1977) taxonomy of complaint behaviour, $80.1 \%$ of the respondents indeed took action, while $19.9 \%$ did not take any action. However, Table 1 illustrates that, although proportionately more responses were obtained for problem-focussed coping than for emotion-focussed coping and avoidance coping $(\mathrm{p}=0.0007)$, only $29.4 \%$ of the responses were obtained for directly contacting retailers to obtain redress $(19.5 \%)$ and for other reasons than seeking redress $(9.9 \%)$. Attribution of blame alone therefore does not predict an obvious coping strategy that could address the problem. In fact, most of the responses (59.7\%) were obtained for engaging in emotion-focussed coping by telling others about the bad experience (27.4\%), and engaging in avoidance coping by switching brands (14.2\%), by no longer patronising the retailer (10.5\%) or by taking no action (7.6\%).

The question is: why? Lazarus and Lazarus (1994, p. 144) note that appraisal is in fact an active negotiation between one's personal agenda and the characteristics of the environment - in this case 
what the product failure personally means for the consumer (also in terms of the emotions that it evokes) and the complaint environment. Personal meaning which arouses emotions is therefore the product of the appraisal.

Table 1 Coping strategies in terms of complaint actions

\begin{tabular}{|c|c|c|c|c|c|}
\hline Coping strategies \& CCB & $\begin{array}{l}\text { Number } \\
\text { of } \\
\text { responses }\end{array}$ & $\begin{array}{c}\% \\
n 1=563\end{array}$ & $\begin{array}{c}\text { Total } \\
\text { responses }\end{array}$ & $\begin{array}{c}\% \\
\text { n1 }=563\end{array}$ & $\begin{array}{c}\text { p-value } \\
\text { Chi }^{2} \text {-test } \\
\text { for equal } \\
\text { proportions }\end{array}$ \\
\hline \multicolumn{5}{|l|}{ Emotion-focused coping } & \multirow{13}{*}{$0.0007 *$} \\
\hline $\begin{array}{l}\text { Told friends, family and/or } \\
\text { acquaintances about the bad } \\
\text { experience }\end{array}$ & 154 & 27.4 & 154 & 27.4 & \\
\hline \multicolumn{5}{|l|}{ Avoidance coping } & \\
\hline $\begin{array}{l}\text { Decided to use another brand } \\
\text { name }\end{array}$ & 80 & 14.2 & \multirow[t]{3}{*}{182} & \multirow[t]{3}{*}{32.3} & \\
\hline $\begin{array}{l}\text { Stopped supporting the retailer } \\
\text { where the appliance was } \\
\text { purchased }\end{array}$ & 59 & 10.5 & & & \\
\hline Took no action & 43 & 7.6 & & & \\
\hline \multicolumn{5}{|l|}{ Problem-focused coping } & \\
\hline $\begin{array}{l}\text { Contacted the } \\
\text { retailer/manufacturer to obtain } \\
\text { redress } \\
\text { (repairs/replacement/refund) }\end{array}$ & 110 & 19.5 & \multirow[t]{6}{*}{227} & \multirow[t]{6}{*}{40.3} & \\
\hline $\begin{array}{l}\text { Contacted the } \\
\text { retailer/manufacturer to complain } \\
\text { for reasons other than seeking } \\
\text { redress }\end{array}$ & 56 & 9.9 & & & \\
\hline $\begin{array}{l}\text { Contacted a repair service other } \\
\text { than that supplied by the retailer } \\
\text { or manufacturer }\end{array}$ & 55 & 9.8 & & & \\
\hline $\begin{array}{l}\text { Contacted a consumer protection } \\
\text { organisation/department }\end{array}$ & 3 & 0.5 & & & \\
\hline $\begin{array}{l}\text { Wrote a letter to the press } \\
\text { (newspaper, magazine etc.) or to a } \\
\text { consumer complaint website }\end{array}$ & 2 & 0.4 & & & \\
\hline Contacted a legal representative & 1 & 0.2 & & & \\
\hline Total & 563 & 100.0 & 563 & 100.0 & \\
\hline
\end{tabular}

Respondents' level of anger and reasons for engaging in specific coping strategies were measured. Since few responses were obtained for third-party complaint action, it was excluded from the statistical analysis. It is clear from Table 2 that very high to extremely high levels of anger were experienced in all the cases where consumers took action, with strong relationships between the intensity of anger and the various types of coping strategies $(p<0.0001)$. Table 2 also shows that most of the respondents were very angry to extremely angry in all of the cases where they took action, with 
strong relationships between the intensity of anger experienced and the various types of coping strategies $(\mathrm{p}<0.0001)$. The highest levels of anger were experienced by those consumers who contacted the retailer or manufacturer for other reasons than seeking redress (for example, to vent their anger), who decided to use another brand name and who decided to stop supporting the retailer. Although none of these actions could solve the immediate problem, it could restore a damaged ego, which in many cases might have triggered the anger (Lazarus and Lazarus, 1994:20). As in the case of telling friends or family about the bad experience or contacting the retailer or manufacturer for redress, it could reduce negative feelings toward the manufacturer who is to blame for the problem. In terms of cognitive appraisal theory, the findings therefore confirm that emotions arise in response to the appraisal one makes for the injustice suffered (anger as a result of blaming the manufacturer or product). Once elicited, these emotions prepare one to cope in an adaptive manner, although not necessarily solving the immediate problem. In this case the respondents had to evaluate the potential for and the consequences of engaging in a specific coping strategy.

Table 2 Intensity of anger experienced in relation to the types of coping strategies and complaint actions

\begin{tabular}{|c|c|c|c|c|c|}
\hline \multirow[t]{2}{*}{$\begin{array}{l}\text { Types of coping strategies and complaint } \\
\text { actions }\end{array}$} & \multirow[t]{2}{*}{$\mathbf{n}$} & \multicolumn{3}{|c|}{$\begin{array}{c}\text { Level of anger experienced } \\
\%\end{array}$} & \multirow{2}{*}{$\begin{array}{c}\text { p-value } \\
\text { Chi' }^{2} \text {-test } \\
\text { for equal } \\
\text { proportions }\end{array}$} \\
\hline & & $\begin{array}{l}\text { Not angry } \\
\text { at all }\end{array}$ & $\begin{array}{l}\text { Reasonably } \\
\text { angry }\end{array}$ & $\begin{array}{l}\text { Very to } \\
\text { extremely } \\
\text { angry }\end{array}$ & \\
\hline \multicolumn{6}{|l|}{ Emotion-focused coping } \\
\hline $\begin{array}{l}\text { Told friends, family and/or acquaintances } \\
\text { about the bad experience }\end{array}$ & 154 & 6.4 & 33.8 & 59.8 & $<0.0001$ \\
\hline \multicolumn{6}{|l|}{ Avoidance coping } \\
\hline Decided to use another brand name & 80 & 6.2 & 25.4 & 69.5 & $<0.0001$ \\
\hline $\begin{array}{l}\text { Stopped supporting the retailer where the } \\
\text { product was purchased }\end{array}$ & 59 & 6.2 & 25.0 & 68.8 & $<0.0001$ \\
\hline Took no action & 43 & 21.4 & 47.6 & 31.0 & 0.1092 \\
\hline \multicolumn{6}{|l|}{ Problem-focused coping } \\
\hline $\begin{array}{l}\text { Contacted the retailer/manufacturer to obtain } \\
\text { redress }\end{array}$ & 110 & 2.8 & 38.2 & 59.0 & $<0.0001$ \\
\hline $\begin{array}{l}\text { Contacted the retailer/manufacturer to } \\
\text { complain for other reasons than seeking } \\
\text { redress }\end{array}$ & 56 & 7.1 & 17.9 & 75.0 & $<0.0001$ \\
\hline $\begin{array}{l}\text { Contacted a repair service other than that } \\
\text { supplied by the retailer or manufacturer }\end{array}$ & 55 & 1.8 & 43.6 & 54.6 & $<0.0001$ \\
\hline
\end{tabular}

The respondents' reasons (in terms of emotional and cognitive reasoning) for engaging in specific coping strategies and the relationship between the specific reasons and the choice of coping strategies 
were therefore also determined (Table 3). The reasons why respondents engaged in the emotionfocussed coping strategy by talking to others about the problem were mostly related to emotional reasoning $(\mathrm{p}<0.0001)$. These respondents dealt with their negative emotions rather than with the physical problem per se. The respondents who engaged in avoidance coping by switching to another brand name or by boycotting the retailer, mainly did so for cognitive reasons ( $\mathrm{p}<0.0001$ ), because they felt that they could not trust the retailer or the brand name any more. Although they experienced high levels of anger (Table 2), they opted for avoidance coping, partly to reduce their anger, but more significantly to prevent further problems and frustrations, although it could not solve the immediate problem.

Where respondents decided to engage in problem-focussed coping by contacting the retailer for redress, they did so because of cognitive reasons, mainly because the appliance was still under guarantee, explaining why they most probably did not experience the highest levels of anger (Table 3). This confirms that appraisal is not only about who is to be blamed, but also about the impact on one's well-being and the probability that one could cope successfully in the environment. This then also reduces the level of negative emotions (anger) and restores the feeling of well-being.

Although most of the reasons why respondents decided to contact the retailer for other reasons than redress, could theoretically be categorised as cognitive reasoning, the effect of engaging in this type of reasoning on the person's emotional state could not be ignored. Cognitive appraisal theory emphasises the inter-relationship between cognitions and emotions and the choice of a coping strategy that could attribute to the person's feeling of well-being, although not necessarily solving the actual physical problem.

The decision to contact a separate repair service (associated with the problem-focused coping strategy) was directed by cognitive reasoning only. Respondents mainly contacted a repair service because their households could not function properly without their specific appliances and their appliance guarantees had expired, which meant that the retailers/manufacturers concerned were no longer responsible for their appliance.

Only cognitive reasons were given by the respondents who took no action. They mostly thought that it was not worth the time and effort to take action. 
Table 3 Reasons for taking specific actions in terms of type of reasoning and coping strategy

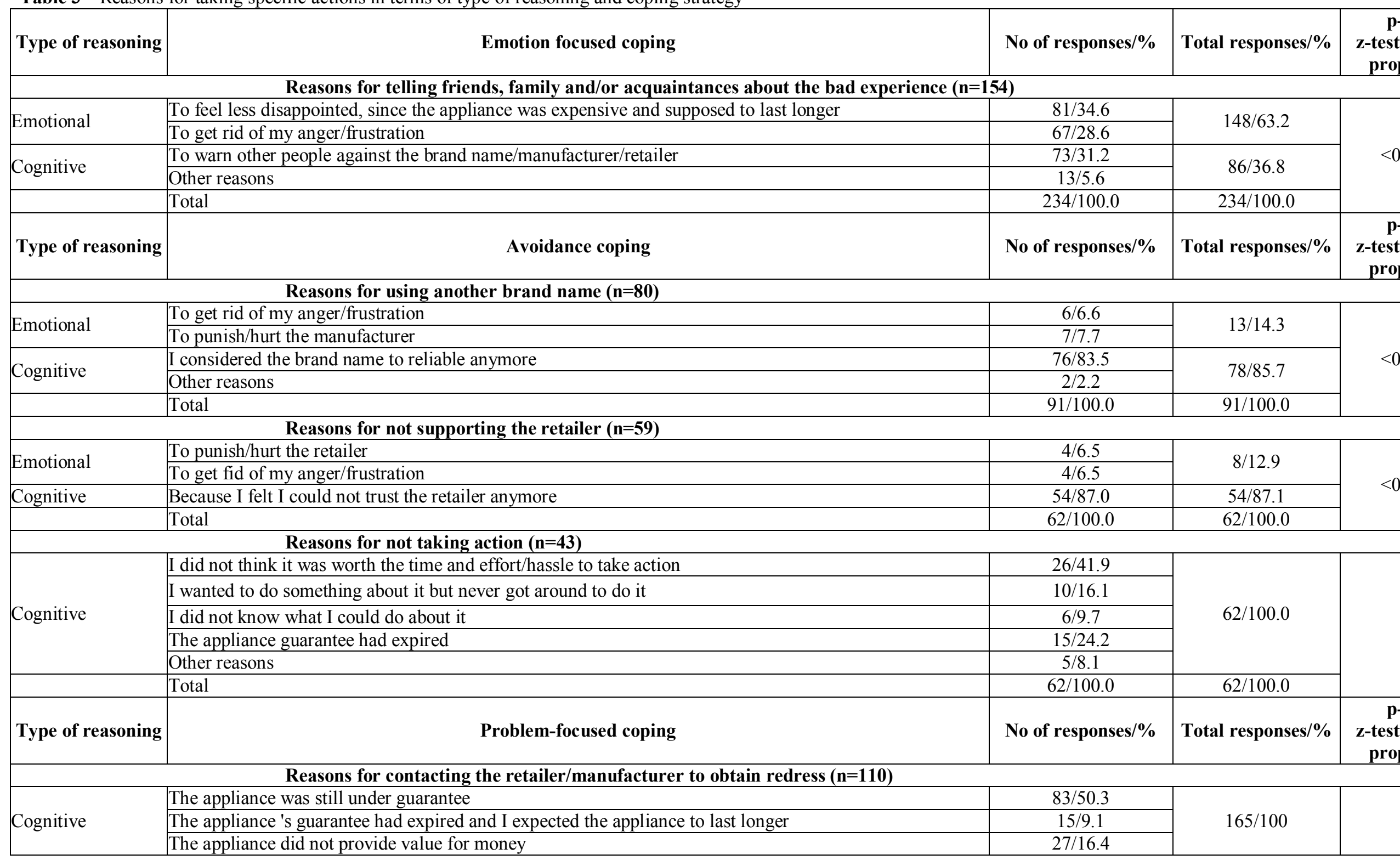




\begin{tabular}{|c|c|c|c|c|}
\hline & The household could not function properly without the appliance & $40 / 24.2$ & & \\
\hline & Total & $165 / 100$ & $165 / 100$ & \\
\hline \multicolumn{5}{|c|}{ Reasons for contacting the retailer/manufacturer to complain for reasons other than seeking redress $(n=56)$} \\
\hline Emotional & To get rid of my anger/frustration & $10 / 11.4$ & $10 / 11.4$ & \\
\hline \multirow{4}{*}{ Cognitive } & To make and objection after my effort to obtain redress/compensation for the appliance failed & $19 / 21.6$ & \multirow{4}{*}{$78 / 88.6$} & \\
\hline & To stand up for my rights as a consumer & $37 / 42.1$ & & \\
\hline & To get an apology from the retailer/manufacturer & $20 / 22.7$ & & $<0$ \\
\hline & Other reasons & $2 / 2.2$ & & \\
\hline & Total & $88 / 100$ & $88 / 100$ & \\
\hline \multicolumn{5}{|c|}{ Reasons for contacting a repair service other than that supplied by the retailer or manufacturer $(\mathrm{n}=55)$} \\
\hline \multirow{5}{*}{ Cognitive } & $\begin{array}{l}\text { The appliance's guarantee had expired and the retailer/manufacturer was not responsible for the appliance } \\
\text { anymore }\end{array}$ & $37 / 37.0$ & \multirow{4}{*}{$81 / 100$} & \\
\hline & The household could not function properly without the appliance & $31 / 38.3$ & & \\
\hline & The repair service was less expensive than the retailer/manufacturer's service & $16 / 19.8$ & & \\
\hline & Too much trouble to go back to the retailer or manufacturer & $4 / 4.9$ & & \\
\hline & Total & $81 / 100$ & $81 / 100$ & \\
\hline
\end{tabular}

* p-value: significant at $\mathrm{p}<0.05$ 
Respondents mostly attributed appliance failures to the "wrongdoing" of manufacturers and were mostly very angry to extremely angry. Most of the respondents engaged in some form of formal or private complaint action regarding appliance failures. Those who did take formal action, engaged in problem-focused coping by contacting retailers directly to obtain redress, mostly because their appliances were still under guarantee, or by contacting retailers to make objections, to fight for their consumer rights and to get apologies. These actions were mainly driven by cognitive reasoning. Unfortunately, less than a quarter of the respondents chose this type of problem-focused coping behaviour, leaving the retailer in the dark about the problem and in no position to address the problem. Respondents who took private action, engaged in emotion-focused coping by telling others about the problem to get rid of their frustration and to warn others against the brand name/manufacturer/retailer. In addition, respondents complained in private by boycotting brands and retailers or by refraining from taking action, implying avoidance coping. Respondents decided to boycott brands and retailers because they felt they could no longer trust them. These coping strategies were mainly directed by cognitive reasoning and accompanied by very high to extremely high levels of anger, but can also be seen as an act of vengeance against the manufacturer or retailer to restore their (the consumers') wounded egos. Those who refrained from taking any action experienced lower levels of anger and believed that it was not worth the time and effort to take action, implying that they were probably of the opinion that the retailers would do nothing about the problem.

It should be noted that the highest levels of anger were experienced by those respondents who contacted the retailer and manufacturer for other reasons than obtaining redress (i.e. problem-focused coping) as well as those who boycotted retailers and brands (i.e. avoidance coping). They did so mainly because they wanted to object, stand up for their rights and get an apology, felt they could not trust the retailer anymore and no longer considered the brand name to be reliable. The reasons for these actions were driven mainly by cognitive reasoning and should be regarded as "valid reasons" for engaging in these actions. However, these actions also indirectly empower consumers to do something about their frustration and anger. 
The results emphasise the importance of understanding consumers' secondary appraisals, in this case their reasoning (whether emotion-driven or cognition-driven) behind their choice of a specific coping strategy. Retailers should realise that consumers' appraisals of product failures involve cognitive activity that is accompanied by specific emotions. The interplay between the consumers' cognitions and emotions facilitates specific behavioural responses to cope with the stress caused by product failure. Consumers can withdraw from the situation or deal with the problem squarely, and/or engage in negative word of mouth communication to their family and friends to deal with their emotions - actions that have consequences for both the consumer and the retailer. When consumers avoid taking action or boycott retailers, the latter will never know about the consumers' dissatisfactions, and will therefore never be able to rectify product problems. In contrast, complaints directed at retailers provide them with the opportunity to get into the hearts and minds of customers and to correct product problems, which is vital for the continuation of long-term relationships with customers. Consumers mainly engage in negative word of mouth to seek social support and to vent anger; however, this type of communication is detrimental to retailers and manufacturers since it can damage the company's reputation, resulting in the loss of potential and existing consumers.

Retailers' complaint handling policies and procedures should form part of their marketing strategy so as to inform the customer about their positive attitude towards complaining as well as their ability to solve a specific problem. That could restore the consumer's trust in the retailer or brand and could encourage the consumer to complain directly to the retailer or manufacturer, instead of taking their business elsewhere. Customer involvement and personal attention and communication (not only activity based, but also psychologically based) are important dimensions in relationship marketing and retailers' attempts to retain loyal customers. Marketers and retailers should keep in mind that complaint handling is not only about repaying "redress seekers", but about managing the whole process. Firstly it is about understanding product failures from the customers' point of view, secondly about understanding how they appraise the stressful situation, and thirdly about understanding their emotions and behaviour. Only then can decisions be taken as to how to address the problem that the customer is experiencing and how to give them the required emotional support. 


\section{References}

Bagozzi, R.P., Gopinath, M. \& Nyer, P.U. (1999) The role of emotions in marketing. Academy of Marketing Science, 27, 184-206.

Bagozzi, R.P., Gürhan-Canli, Z. \& Priester, J.R. (2002) The social psychology of consumer behaviour. Open University Press, NY, USA.

Broadbridge, A. \& Marshall, J. (1995) Consumer complaint behavior: the case of electrical goods. International Journal of Retail \& Distribution Management, 23, 8-18.

Crié, D. (2003) Consumers' complaint behaviour. Taxonomy, typology and determinants: towards a unified ontology. Journal of Database Marketing \& Customer Strategy Management, 11, 60-79.

Day, R.L. \& Landon, E.L. (Jr.) (1977) Towards a theory of consumer complaining behaviour. In: Consumer and industrial buying behaviour (ed. by A.G. Woodside, I.N. Sheth \& P.D. Bennet), pp. 229-242. North-Holland, NY, USA.

Del Río-Lanza, A.B., Vázquez-Casielles, R. \& Díaz-Martín, A.M. (2009) Satisfaction with service recovery: perceived justice and emotional responses. Journal of Business Research, 62, 775-781.

Donoghue, S. (2008) An explanation of consumer complaint behaviour concerning performance failure of major electrical household appliances, $\mathrm{PhD}$ thesis, University of Pretoria, SA.

Donoghue, S. \& De Klerk, H.M. (2009) The right to be heard and to be understood: a conceptual framework for consumer protection in emerging economies. International Journal of Consumer Studies, 33, 456-467.

Folkman, S., Lazarus, R.S., Dunkel-Schetter, C., Delongis, A. \& Gruen, R.J. (1986) Dynamics of a stressful encounter: Cognitive appraisal, coping and encounter outcomes. Journal of Personality and Social Psychology, 50, 992-1003.

Forrester, W.R. \& Maute, M.F. (2001) The impact of relationship satisfaction on attributions, emotions and behavior following service failure. Journal of Applied Business Research, 17, 1-14.

Huppertz, J.W. (2003) An effort model of first-stage complaining behaviour. Journal of Consumer Satisfaction, Dissatisfaction and Complaining Behavior, 16, 132-144.

Johnson, A.R. \& Stewart, D.W. (2005) A reappraisal of the role of emotion in consumer behaviour. Traditional and contemporary approaches. In: Review of Marketing Research (ed. by N.K. Malhotra), pp 3-34. M.E. Sharpe, Armonk, NY, USA.

Kim, C., Kim, S., Im, S. \& Shin, C. (2003) The effect of attitude and perception on consumer complaint intentions. Journal of Consumer Marketing, 20, 352-371. 
Kim, M.G., Wang, C. \& Mattila, A.S. (2010) The relationship between consumer complaining behaviour and service recovery. An integrative review. International Journal of Contemporary Hospitality, 22, 975-991.

Laufer, D. (2002) Are antecedents of consumer dissatisfaction and consumer attributions for product failures universal? Advances in Consumer Research, 29, 312-317.

Lazarus R.S. \& Folkman, S. (1984) Stress, appraisal and coping. Springer, NY, USA.

Lazarus, R.S. \& Lazarus, B.N. (1994) Passion and reason. Making sense of our emotions. Oxford University Press, NY, USA.

Mathur, A., Moschis, G.P. \& Lee, E. (1999) Stress and consumer behaviour. Coping strategies of older adults. Journal of Marketing Practice, 5, 233-247.[‘362 1mn6 sed ert6y77 7

Nieftagodien, S. \& Van der Berg, S. (2007) Consumption patterns and the black middle class: The role of assets. Stellenbosch Economic Working Paper 2/2007. Department of Economics \& Bureau for Economic Research, University of Stellenbosch, SA.

Nyer, P.U. (1997) A study of the relationships between cognitive appraisal and consumption emotions. Journal of the Academy of Marketing Science, 25, 296-304.Oliver, R.L. (1980) A Cognitive model of the antecedents and consequences of satisfaction decisions. Journal of Marketing Research, 17, 460-469.

Soscia, I. (2007) Gratitude, delight, or guilt: the role of consumers' emotions in predicting post-consumption behaviours. Psychology \& Marketing, 24, 871-894.

Stephens, N. \& Gwinner, K.P. (1998) Why don't some people complain? A cognitive-emotive process model of consumer complaint behavior. Journal of the Academy of Marketing Science, 26, 172-189.

Watson, L. \& Spence, M.T. (2007) Causes and consequences of emotions on consumer behaviour. A review and integrative cognitive appraisal theory. European Journal of Marketing, 41, 487-511.

Weiner, B. (2000) Attributional thought about consumer behavior. Journal of Consumer Research, 27, $382-387$. 